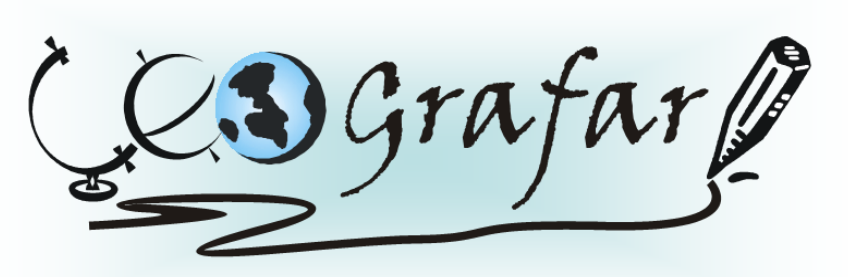

Revista Eletrônica do Programa de Pós-Graduação em Geografia - UFPR

\title{
O CINEMA DE JIA ZHANGKE E A CONSTRUÇÃO DE UMA GEOGRAFIA HUMANA SENSÍVEL
}

\section{JIA ZHANGKE'S CINEMA AND THE CONSTRUCTION OF A SENSITIVE HUMAN GEOGRAPHY \\ (Pesquisador convidado)}

Rafael Faleiros de Padua Doutor em Geografia pela Universidade de São Paulo, Professor do Departamento de Geociências da Universidade Federal da Paraíba. rfpadua@gmail.com

\section{Resumo}

O texto procura apresentar possibilidades de interpretação da realidade contemporânea e de construção de um conhecimento crítico a partir de elementos da obra do cineasta chinês Jia Zhangke. Verificamos que seus filmes, ao retratar de modo extremamente sensível o momento histórico atual da China, onde a transformação do espaço e das relações sociais avança de maneira gigantesca e perturbadora, nos ajudam a compor uma Geografia Humana possível da modernidade contemporânea, quando o espaço e sua produção se colocam no centro das preocupações.

Palavras-chave: cinema, Jia Zhangke, produção do espaço, urbanização, Geografia.

\section{Abstract}

The text seeks to present possibilities of interpretation of contemporary reality and construction of a critical knowledge from elements of the work of the Chinese filmmaker Jia Zhangke. We can see that his films, in an extremely sensitive portrayal of China's current historical moment, where the transformation of space and social relations is moving in a gigantic and disturbing way, help us to compose a possible Human Geography of the present moment of modernity, when the Space and its production are at the center of the concerns.

Keywords: cinema, Jia Zhangke, space production, urbanization, geography

Há alguns anos, final dos anos 1990 ou começo dos anos 2000, quando ainda era estudante em São Paulo, assisti a um curta metragem chinês que me impressionou muito. Mostrava um bairro tradicional em uma grande cidade, provavelmente Pequim, um bairro de ruas estreitas com casas muito próximas umas das outras e talvez com equipamentos compartilhados entre as famílias moradoras. Não era um bairro muito grande, mas também não era pequeno, e quando visto no horizonte parecia um resíduo de espaço tradicional de outro tempo em uma urbanização que já apresentava uma tendência à ocidentalização das suas formas. Não me lembro do enredo do filme, não sei se mostrava os conflitos 
entre os moradores do bairro e os agentes hegemônicos (grupos econômicos e o Estado) interessados naquele espaço estratégico para suas ações de reestruturação da cidade. $O$ fato é que o filme termina mostrando todo o terreno onde se localizava aquele bairro popular com arquitetura tradicional agora sem as construções que constituíam o bairro, que haviam sido destruídas. Agora havia somente um grande terreno vazio pronto para ser tomado como canteiro de obras para a construção de grandes edifícios residenciais e/ou comerciais com uma arquitetura ocidentalizada. Esse filme não foi realizado em um cenário, mas na própria cidade que realmente destruía seus bairros antigos e construía outros modernizados, o que impressionava.

Esse pequeno filme ficou bem presente em minha memória porque o personagem principal é 0 próprio espaço urbano, e o conteúdo era o arrasamento de um espaço tradicional da vida naquela cidade. Questões permaneciam na cabeça do expectador: e a vida das pessoas que viviam ali?, quais as estratégias por trás de tamanha destruição de todo um bairro antigo da cidade? O contexto mais geral já conhecíamos, ao menos parcialmente: era o intenso crescimento econômico chinês a partir das reformas do governo daquele país que promoveram uma abertura da China para a economia capitalista. $O$ filme mostrava então as implicações desse processo na urbanização do país, promovendo um movimento de destruição de imensas áreas antigas para a efetivação da modernização chinesa. O que já chamava a atenção naquele pequeno filme era o papel do espaço nesse movimento de transformação política, econômica e social da China, que representa uma modificação substantiva na morfologia espacial e social, revelada sobretudo nos espaços urbanos.

Apresentaremos nesse texto uma articulação possível entre a preocupação da Geografia em interpretar o espaço e o cinema como possibilidade concreta da apreensão de elementos fundamentais da realidade contemporânea. Dessa maneira, sustentaremos que o cinema é uma fonte importante de informações sobre os fenômenos da realidade e pode ao mesmo tempo ser importante instrumento para a construção de um conhecimento crítico na Geografia, na medida em que se coloca como uma arte complexa e que necessariamente apresenta em suas obras aproximações com as questões cruciais das relações espaço-temporais que movem a realidade contemporânea.

Para tanto, trabalharemos essa articulação a partir de elementos da obra de Jia Zhangke, um cineasta chinês que vem construindo em sua obra cinematográfica uma reflexão profunda sobre as drásticas transformações no espaço e na sociedade da China a partir das últimas décadas do século XX. A obra desse cineasta, embora esteja ligada a uma realidade específica, a chinesa, revela uma universalidade ao buscar nos encontros e desencontros das relações sociais e espaços cotidianos, os nexos da transformação social e espacial. Nessa obra, se revela uma Geografia Humana sensível, onde os personagens e suas relações, assim como o espaço onde vivem são elementos que apontam para os 
conteúdos contraditórios do avanço da privatização compulsória da existência, regida pelas determinações da reprodução do modo de produção capitalista em sua fase atual.

A Geografia como prática concreta é feita a partir do corpo e dos sentidos humanos, portanto se apresenta como um conhecimento que pode ajudar a desvendar as drásticas mudanças vividas na contemporaneidade. Uma preocupação central de Jia Zhangke é com a construção das individualidades em um contexto de mudanças radicais nas referências da vida. A sua obra parte justamente de um incômodo com a velocidade e a amplitude das transformações das relações sociais e do espaço na sua cidade e de seus lugares habituais (ZHANGKE, 2014). Nesse sentido, é o espaço da vida sendo revolvido, destruído e reconstruído em novas bases de funcionamento e é a perplexidade dos indivíduos diante do abismo que se abre em suas existências, nas suas relações e em seus espaços mais próximos.

Muitos filmes são analisadores das dinâmicas espaciais e permitem novas interpretações sobre os conteúdos das transformações que se dão nos espaços da vida. No cinema, a aproximação com a materialidade é um aspecto a ser observado no processo de construção das representações possíveis sobre a realidade que se metamorfoseia continuamente na modernidade. Talvez o cinema seja a forma de arte ou de representação da vida social que mais se aproxime do cotidiano, porque na sua composição de imagem e som estão necessariamente o espaço e o tempo se realizando concretamente na prática dos personagens ou na história proposta por cada filme. Desse modo, o cinema pode ajudar muito na construção de significados sobre o movimento da realidade, mesmo quando esse movimento está no momento presente, o que é o caso de alguns dos filmes de Jia Zhangke. Para Walter Salles, fazendo uma reflexão sobre o filme Plataforma (2000), que mostra um grupo de jovens atores percorrendo uma região do norte da China e vão se transformando nesse processo, junto com as transformações do país,

A ação do tempo na vida dos personagens é muitas vezes silenciosa. Em outros momentos, é brutal. 0 mundo interior, o dos personagens, vai ruindo ao mesmo tempo que a cidade feudal onde eles vivem vai se transformando em um canteiro de obras, reflexo de uma modernização realizada a fórceps. Jia Zhangke mostra esse processo de desestruturação e de perda de identidade, tanto pessoal quanto coletivo, sem jamais julgar o que vemos. Nenhuma trajetória se quer exemplar. Seus personagens são apenas testemunhas de seu tempo, de algo que não mais será. A câmera torna possível o registro de uma memória coletiva, a memória de como se viveu em um momento de transformações tão turbulentas (SALLES, 2014: 47-48).

A prática social humana é necessariamente espacial, pois se realiza no espaço, produzindo 0 espaço. A Geografia como campo mais ou menos específico procura produzir um conhecimento sobre a realidade a partir da dimensão espacial da sociedade. Assim ela é um esforço mais elaborado pela compreensão do porquê os elementos do espaço estão onde estão e como eles foram produzidos espacialmente. A pesquisa sobre o espaço busca portanto os fundamentos da produção do espaço, que 
é resultado do processo histórico de produção da sociedade. Essa compreensão ganha potência quando vista a partir do âmbito mais próximo do lugar, recurso que o cineasta chinês utiliza em seus filmes.

O cineasta em questão, Jia Zhangke, nasceu em 1970 em uma cidade do interior da China, Fenyang, na província de Shanxi, filho de funcionários públicos, o pai professor de línguas e a mãe funcionária de uma companhia de açúcar e fumo. Há muitas referências em sua obra sobre sua terra natal, onde passou muitos anos da infância até o começo da idade adulta, quando vai para Pequim estudar na Academia de Cinema. Viveu, portanto, a realidade anterior ao processo de intensas modificações advindas com as reformas de Deng Xiaoping em meados da década de 1970 e viveu e vive todo o movimento que vem modificando radicalmente o espaço e a vida dos chineses a partir de então. Relembrando sua vida em Fenyang, o cineasta diz que:

Os prédios onde cresci continuam lá, mas foram transformados: antigamente as habitações não eram separadas como agora, não havia todas essas paredes e muitas famílias moravam aqui sem estar separadas. Ao lado da nossa casa moravam uma familia de militares e um homem que trabalhava numa empresa de transporte, no pátio dos fundos havia operários e camponeses. Todos se davam muito bem, passávamos muito tempo juntos. Os militares chegavam à noitinha com suas histórias do Exército, os operários falavam da fábrica, os camponeses de suas atividades e meu pai da escola. À noite, o pátio se transformava numa praça de vilarejo e as pessoas continuavam a bater papo e a conversar sobre política enquanto comiam (ZHANGKE, 2014: 70).

Podemos dimensionar o processo de transformação vivido pela geração de Jia Zhangke ao compararmos o documentário China, de Michelangelo Antonioni, com os filmes que retratam a realidade contemporânea do país. No documentário de Antonioni, filmado no começo da década de 1970, a China é um país tradicional e com muitas particularidades. As ruas das grandes cidades eram repletas de bicicletas, a urbanização apresentava uma morfologia própria com bairros antigos anteriores à lógica do automóvel, com suas ruas estreitas e suas casas compartilhadas, com pátios internos. As maiores cidades, como Pequim e Xangai, não tinham nada que apontasse para a ocidentalização de sua paisagem, processo que viveriam nas próximas décadas. Os símbolos da Revolução Chinesa estavam presentes por toda parte, seja nas cidades, seja nas regiões camponesas. Algumas cenas podem ilustrar bem esse aspecto da tradicionalidade com características próprias conduzidas pelo regime comunista.

Durante todo o documentário, não se nota diferenças notáveis na população. Nas cenas que a câmera se aproxima mais das pessoas, não notamos nenhuma grande discrepância entre elas, mas uma igualdade das condições de mobilidade, das vestimentas, da moradia, ou da diversão. Duas cenas, entre muitas outras desse extenso documentário podem ser ressaltadas para evidenciar o ritmo, ou a realidade espaço-temporal vivida naquele momento. Em uma grande avenida de Pequim, no meio do fluxo de 
bicicletas, um senhor faz exercícios de tai-chi-chuan em cima de sua bicicleta em movimento. Outra cena mostra um parto de cesárea com anestesia feita com técnicas de acupuntura, medicina tradicional chinesa. Essas cenas ilustram formas de apropriação do espaço e do tempo que serão desestruturadas com as novas condições de reprodução social da China com a abertura para o mercado capitalista.

É esse movimento de passagem que visualizamos nos filmes de Jia Zhangke, que constrói uma obra investigando a transformação qualitativa de um país que se moderniza sobre os escombros de um país em grande medida tradicional, com suas particularidades e permanências (referências). A transformação física dos espaços urbanos e rurais é acompanhada de uma modificação das relações sociais em que a expansão das relações de produção propriamente capitalistas reinventa as sociabilidades, os comportamentos, as relações de amizade, etc. A acumulação capitalista como algo crescentemente almejado, impõe novas mediações para as relações sociais. Segundo Jia Zhangke, "há muitas mudanças nos sistemas de valores. Agora o que está no centro de tudo na China é o dinheiro e todo esse pano de fundo tem uma influência enorme nos sentimentos entre as pessoas"1.

Os filmes de Jia Zhangke mostram o desconforto das pessoas em um contexto onde a realidade social se metamorfoseia velozmente, arrasando o lugar da vida: o descompasso, desencontro de uma realidade que se impõe e a dificuldade das pessoas em se sentirem no seu lugar, onde antes se consideravam em casa. O lugar remete à apropriação concreta do espaço pelo indivíduo enquanto ser social, é a esfera onde as pessoas realizam efetivamente os atos da vida, evidenciadores por sua vez do movimento geral da reprodução social. Esse desconforto, descompasso ou desencontro das pessoas que vêem o seu próprio lugar da vida se transformar em sua forma e conteúdo, assim como uma extensa mobilidade das pessoas pelo espaço parece ser uma característica marcante do mundo moderno contemporâneo. O que chama a atenção no cinema de Jia Zhangke nesse sentido é que ele mostra de maneira extremamente delicada e sensível esse mundo em desagregação, uma realidade sendo destruída por outra realidade que se impõe à revelia dos interesses e desejos dos grupos sociais que vivem essa realidade.

É um cinema que nos desafia a pensar sobre as imagens e as histórias que conta e, mesmo tratando de uma sociedade distante da nossa, nos permite a elaboração de reflexões a respeito de nossa própria realidade. Ou seja, permite uma visualização do alcance da expansão do modo de produção capitalista em nível mundial e como o espaço se coloca como mediação central nesse processo de reprodução. Em seus filmes, esse cineasta constrói uma possibilidade de interpretação, um olhar sobre a própria realidade de transformação da China (e do mundo). Mas sempre tem brechas para as

\footnotetext{
${ }^{1}$ Entrevista de Jia Zhangke a Olivier Père a respeito do filme que o cineasta lançava naquele momento, As montanhas também podem voar, durante o Festival de Cannes de 2015, no canal ARTE France.
} 
interpretações e para a imaginação do expectador, não explica tudo, porque se trata do tempo propriamente humano, mesmo em uma espacialidade e temporalidade cada vez mais cambiantes de maneira veloz. $O$ tempo dos filmes nos permite entrar no olhar dos personagens e nos aproximar da realidade por eles vivida.

Em um de seus filmes mais expressivos e prestigiados, Em busca da vida (2006)², o enredo se passa em Fengjie, cidade histórica às margens do Rio Yang-tsé, na região central da China, no momento em que era construída a grande hidrelétrica de Três Gargantas, que inundaria parte da cidade, que estava sendo demolida até a cota de inundação da barragem. A história mostra personagens em busca de reatar laços familiares nesse contexto de intensa modificação do espaço. Um dos personagens migra de sua região distante para encontrar sua filha e sua mulher, e começa a trabalhar na demolição de prédios. Outra personagem chega também à região em busca de notícias do marido, executivo de uma empresa que está atuando ali. Parece que a realidade pessoal desses personagens se coaduna com a realidade em desagregação do lugar. Legiões de trabalhadores precários migrantes vindos de várias regiões do país para trabalhar na região de impacto da grande obra vivem em condições de absoluta pobreza, mas ao mesmo tempo encontram certo conforto numa solidariedade possível entre colegas, quando relembram suas regiões de origem. Por outro lado executivos de empresas estatais aparecem em inauguração de obra monumental que representa a nova pujança da China atual. No entanto essa potência é contraditória com a vida concreta dos personagens que parecem sem pistas para a retomada de suas vidas. Sobre Em busca da vida, o cineasta diz que,

Acho que o filme conseguiu captar em tempo real algo das transformações da China, mas com uma inquietação ainda maior, que concerne ao ser humano. A inquietação de ver os homens desaparecerem, e a inquietação de ver a memória se apagar. Quanto ao espaço, ao espaço que traz em si nossa memória e quero filmar, me parece que esse filme conseguiu alguma coisa. Quanto às pessoas, sinto grande pesar, considero que ainda estou longe de onde seria preciso chegar para fazer jus tanto ao que as pessoas sofrem quanto à sua força de vida, à sua beleza (ZHANGKE, 2014: 139-140).

Assim, esse filme é exemplar no sentido de permitir a elaboração de uma perspectiva crítica sobre o desenvolvimento chinês contemporâneo, revelando através das particularidades de um lugar em transformação, o movimento de esboroamento das permanências, das referências sociais, na medida em que uma nova totalização da reprodução social impõe determinações que se assentam na mobilização de espaços para estratégias globais, que se ligam à ideia de progresso, de tornar o país uma potência, como justificativa de todo esse processo.

2 Lançado em 2006, esse filme ganhou o Leão de Ouro (melhor filme) no Festival de Veneza de 2006. 
O avanço das estratégias espaciais sobre os espaços tradicionais, impondo o tempo rápido das necessidades do crescimento econômico implica na simultaneidade de diferentes temporalidades se realizando conflituosamente na vida concreta dos grupos sociais. Os descompassos, as rupturas e permanências são apreensíveis no cotidiano ou infra-cotidiano vivido pelos personagens no filme, nos seus atos da vida, nas suas buscas interrompidas, nas privações, que carregam a significação do movimento da realidade. É a partir dessa aproximação possivel com esse processo de transformação visto por dentro, que podemos ver o que se modifica e o que permanece e irmos em direção aos conteúdos desses descompassos.

As permanências e rupturas se realizam conjuntamente, de forma articulada e contraditória, pois são relações sociais diferentes, de diferentes temporalidades, que expressam diferentes formas de apropriação e apreensão do mundo. Quando vemos no filme Em busca da vida os operários trabalhando e morando em condições precárias para a realização de um enorme projeto que seria fundamental para a modernização da China, já podemos avançar para os conteúdos contraditórios desse processo de modernização. Percebemos na destruição da cidade para dar lugar ao lago da hidrelétrica como as relações sociais se estabelecem nesse espaço de escombros. As determinações gerais que apontam para a busca do crescimento econômico acelerado fazem com que grandes quantidades de trabalhadores se desloquem para trabalhar em outras regiões, em atividades que o contexto socioeconômico geral lhes possibilita. É dessa forma que regiões camponesas são urbanizadas ou despovoadas e que os camponeses se tornam trabalhadores precários na cidade, como se pode ver no filme. Nesse mesmo sentido, regiões urbanas tradicionais nas cidades mais antigas vão sendo arrasadas para dar lugar a grandes conjuntos de edifícios de habitação ou de escritórios, ou ainda shoppings centers, avenidas, rodovias, etc.

Trata-se da passagem de uma realidade grandemente derivada de tradições sociais (e de espaços de outros tempos) permanentes, antigos, substâncias de referências sociais, para a instabilidade, tanto do espaço como das relações sociais. Nos filmes de Jia Zangke visualizamos a destruição de grandes espaços e o assombro das pessoas diante desse movimento que os envolve e que Ihes interdita qualquer chance de escolha. Agora se trata de uma transitoriedade permanente, expressiva em uma realidade evanescente, realizando os imperativos de uma lógica abstrata sempre exterior aos moradores antigos dos lugares (porque sempre "nova"), exigente de um movimento contínuo das mercadorias, das pessoas, enfim, do próprio espaço.

Agora a metamorfose do espaço da vida e das práticas sócioespaciais se tornam mediações fundamentais para a transformação do país em uma potência econômica. 0 espaço em constante metamorfose é um personagem desse cineasta e a velocidade acelerada da transformação espacial é 
muitas vezes um outro em relação aos personagens e os inquieta e assombra. Há sempre um incômodo ou um descompasso entre a vivência concreta da realidade cambiante e o olhar dos personagens diante da impermanência do espaço. Esse movimento que os envolve e metamorfoseia de forma determinante a vida aparece agora como se fosse um fluxo inexorável ao qual todos estão necessariamente submetidos. Muitas vezes essa transformação "inexorável" não tem cara, pois é o mundo e o "progresso" que chegaram aos lugares. Mas essa condição espacial que é também a fugacidade das relações sociais que antes eram mais sólidas e perenes é interpretada pela vida concreta das pessoas, no inadequamento aos novos códigos sociais (cada vez mais abstratos) que se impõem na sua existência.

A atualização ou adaptação da realidade chinesa ao tempo da globalização implica uma mudança radical dos pressupostos da vida social. Novas temporalidades e espacialidades impostas através da produção avassaladora do espaço revelam novas formas de sociabilidade vividas em novas morfologias espaciais. A produção do espaço toma uma grande importância no conjunto da reprodução social chinesa, agora dominada por pressupostos do modo de produção capitalista. Novas contradições são produzidas e elas são evidenciadas nos filmes pelo olhar de quem está vivendo esse processo de destruição/reconstrução do espaço e suspensão das relações sociais que até pouco tempo atrás mantinham alguma estabilidade. $O$ conflito imediato e as contradições no nível da reprodução social são apreendidos nos filmes não no espaço em si, mas na vida e no olhar dos personagens diante desse contexto. A potência do cinema de Jia Zhangke está na sensibilidade de revelar uma Geografia Humana a partir do olhar de quem está vivendo concretamente as privações, os conflitos e que apontam as contradições em seus fundamentos.

Com isso, esse cinema pode ser revelador dos conteúdos da modernidade contemporânea, não somente da realidade chinesa, mas também do papel da produção do espaço na reprodução das relações de produção na escala mundial. A realidade chinesa nos parece ser 0 caso mais agressivo nesse sentido hoje, pela sua magnitude e pela velocidade de transformação da realidade social.

O espaço faz parte dos filmes desse cineasta implicado em sua realidade. Mas mesmo que 0 espaço seja elemento essencial, o conteúdo das transformações espaciais está nas relações entre as pessoas, que são reveladoras de muitos outros conteúdos para além da imediaticidade que está na tela. O ponto de vista privilegiado é geralmente o dos indivíduos em suas relações próximas, nos seus lugares da vida ou em seus deslocamentos em busca de pessoas amadas, em busca de uma vida melhor, de trabalho, etc. Mas nesses enredos da proximidade com a vida dos personagens é o mundo, o espaço e o lugar que estão em um processo de transformação determinante de uma nova realidade que se impõe.

Um de seus filmes que mais se aproxima da ideia do processo de globalização que envolve a China nesse momento histórico é 0 mundo (2004), que é um grande parque de atrações na periferia de 
Pequim. Nesse parque são reproduzidas grandes atrações mundiais em escala reduzida em relação ao original, como a Torre Eiffel, ou o Taj Mahal, sugerindo a ideia de que o mundo estaria ali. Nesse parque também são realizados grandes espetáculos. Para Walter Salles, analisando o filme O Mundo, diz que, "Apequenado e ao mesmo tempo gigantesco, o parque de O Mundo é a representação da implosão do tempo e do espaço trazida pela globalização. Não há mais além, distância entre latitudes tão diversas" (SALLES, 2014: 51).

O filme centra sua atenção nos funcionários e funcionárias desse parque gigantesco, revelando o cotidiano de bailarinas, atrizes, guardas, operários da construção, sendo uma metáfora do processo de globalização no sentido de que há uma homogeneização da paisagem (aquele lugar pode ser em qualquer lugar, indiferente) e também uma normatização das relações sociais, que respeita a lógica da produção econômica, que também é indiferente com em relação às necessidades humanas concretas. O conjunto dos funcionários permanece quase todo o tempo da vida no parque, sendo aquele seu mundo real.

Nesse nível próximo da vida revelam-se as cisões impostas por este mundo "novo", o sofrimento com as separações das pessoas queridas em função do trabalho, as interdições na realização de relações concretas entre as pessoas, a grande exploração do trabalho, entre muitas outras questões possíveis de serem apreendidas. Revela um cotidiano massacrado e empobrecido, ditado pela realização automática do "mundo" que coloca todo o seu peso sobre os indivíduos cada vez mais solitários e sem horizontes. Assim, a abertura para o "mundo" é também o esfarelamento das individualidades e a instauração cada vez mais forte do individualismo, já que a mediação das relações sociais passa a ser exercida por questões abstratas, exteriores à realização concreta dos indivíduos. Segundo Antony Fiant, citando uma entrevista do próprio Jia Zhangke:

\footnotetext{
Vemos bem com todos esses exemplos que a passagem à privatização e ao liberalismo, é aquela do coletivismo ao individualismo. Em 2002, Jia a resume assim: "Desde o fim do período da Revolução Cultural, entramos em um período de reforma. Esse período de vinte anos que nos leva até hoje, é o que se chama a Nova Época ou a Nova Era. O que caracteriza os chineses nesse período de vinte anos, é o esforço realizado por todo o mundo para chegar a uma tomada de poder pelo indivíduo, enquanto que outrora o homem na China era somente uma parte do coletivo, um elemento da sociedade. Agora tendemos a ter a individualidade. [...] Agora, nesse período de progressos intensos que vai em uma enorme velocidade, nós nos encontramos face a novos problemas que, no plano cultural, nós não estamos armados para fazer frente ao que nós reivindicamos, que é sobretudo a individualidade (FIANT, 2009, edição digital, sem definição de página).
}

A contradição entre a realização do "mundo" e a realização da vida se coloca com força nos momentos de encontros concretos em que as pessoas que vivem esse processo, às vezes mesmo sem 
falar a mesma língua, compartilham as suas angústias solitárias, revelando a irredutibilidade do humano como troca concreta, mesmo em um contexto em que a troca se torna mais abstrata, mediada por questões quantitativas, sobretudo pelo dinheiro, que cada vez mais povoa as relações sociais.

Como já ressaltamos aqui, o espaço tem uma presença importante na obra de Jia Zhangke. Talvez o filme que mais evidencie a forma como o espaço é tomado por estratégias nesse momento é 24 City (2008). Esse filme, que é uma mistura de ficção e documentário mostra a destruição de uma imensa fábrica para a construção de um grande condomínio, que se chamará "24 City"3. Como o próprio cineasta diz em uma entrevista, a fábrica representava um mundo para os operários, que tinham toda sua vida e de suas famílias garantida por ela. $O$ filme traz depoimentos de antigos operários que mostram essa destruição de espaços da vida como destruição de relações sociais e espaços-tempos qualitativos, mesmo que construídos a partir da realidade organizadora e do controle da indústria. Sobre 24 City, o cineasta afirma que:

Sempre tive vontade de filmar a vida dos operários, principalmente com a transição da economia planejada à economia de mercado nos anos 90 , quando as fábricas foram fechadas e as pessoas mudaram de trabalho. Muitos operários perderam 0 emprego e, depois de ter ocupado uma posição central na sociedade, ficaram marginalizados. A partir daquele momento não houve mais operários na China. Por quê? Porque a vida deles estava estreitamente ligada à da fábrica. A educação deles, de seus filhos, os lazeres, a proteção social, a aposentadoria, as relações de vizinhança e de amizade, tudo era ligado à fábrica. Com a mudança de trabalho, os operários tornaram-se empregados, sem laço afetivo com o local de trabalho. Começaram a pular de uma fábrica para outra. Em 24 City, os operários não perdem o emprego, perdem seu mundo (ZHANGKE, 2014: 144).

Trata-se de filmes que retratam uma realidade da liminaridade entre formas de vida e de representação distintas. Há aí uma tensão constante entre uma prática sócioespacial derivada de uma tradição antiga e muito persistente e uma demolidora nova ordem que se impõe com força inexorável, pois transforma os espaços da vida, ao mesmo tempo que difunde e naturaliza novas formas de representação da realidade. Poderíamos dizer que uma "condição pós-moderna" se impõe mas, no entanto, não destrói completamente as representações de outros tempos.

Para mostrar essa tensão os filmes são desenvolvidos em um tempo lento, que é o tempo humano do olhar para a realidade em transformação. $O$ ritmo é lento também porque ele revela a tensão do olhar humano diante do espaço da vida que se transforma de forma acelerada e cuja concretude é a destruição de lugares e modos de vida. 0 ritmo como realidade espaço-temporal é o ponto de vista ativo/passivo de quem vive dramaticamente esse processo instável onde mesmo espaços milenares

\footnotetext{
${ }^{3}$ A cidade onde se passa esse filme é Chengdu, onde foi destruída a fábrica e construído o gigantesco empreendimento imobiliário.
} 
podem dar lugar a novas formas ocidentalizadas ou mesmo desaparecerem no fundo de um lago de uma das maiores hidrelétricas do mundo.

O ritmo lento é também devido ao fato de que o espaço em muitos momentos aparece quase como um personagem, e os planos sequência devem dar conta de alcançar as extensões e os conteúdos expressos na paisagem em desagregação ou permanência. Há aí uma questão ética presente, que é a de assumir o olhar de personagens que sofrem o aumento da desigualdade decorrente do avanço da privatização acelerada da vida4. Os descompassos entre diferentes morfologias espaciais e as práticas sócioespaciais que lhe são próprias estão presentes nessa dramaturgia espacializada e praticada (ou da prática sócioespacial), porque revela o movimento da destruição e reconstrução no próprio momento em que ele está se realizando (o filme Em busca da vida é muito ilustrativo disso).

As sociedades antigas (milenares) como a China apresentam um enorme repertório cultural acumulado, que persiste em uma estabilidade que tem dificuldades a se mover. O século XX e início do século XXI têm sido um tempo de rupturas nessa cultura milenar. O impacto da Revolução Cultural a partir de meados do século XX e das reformas econômicas promovidas por Deng Xiaoping a partir da década de 1970 constituíram novos encaminhamentos na reprodução social chinesa. O direcionamento do país em direção a uma economia de mercado controlada por um Estado forte irá conduzir um movimento de transformação dos espaços da vida e das práticas sociais em uma dimensão ainda desconhecida na história da humanidade.

Em grande medida, o crescimento acelerado da China está situado no avanço da produção do espaço, revelando uma urbanização galopante do país. Um bom exemplo nesse sentido é o caso de Chongking (ARANTES, 2011), que há algumas décadas era uma pequena cidade situada às margens do grande rio Yang-tsé, no centro da China, e hoje é uma aglomeração de cerca de 36 milhões de habitantes, com todo o aparato que caracteriza uma metrópole com características ocidentais. Estamos diante, portanto, do que Otília Arantes chamou de uma hiperespacialidade chinesa (ARANTES, 2011), que coloca a produção do espaço no centro do debate sobre a modernização desse país.

O contexto das transformações que Jia Zhangke mostra em seus filmes é o do espaço sendo produzido em uma escala nunca vista, em que o modo de apropriação e de representação do espaço também se metamorfoseiam. As grandes cidades se tornam canteiros de obras, com extensos processos de destruição de morfologias antigas e construção de novos equipamentos. A jornalista Cláudia Trevisan escreve que,

\footnotetext{
${ }^{4}$ José de Souza Martins, no livro A Sociedade Vista do Abismo, afirma que os conteúdos da realidade social são melhor apreensíveis a partir do olhar dos grupos sociais que vivem as contradições de maneira determinante em sua vida, como privações nas suas condições de existência.
} 
"Na China, não se constrói um único prédio de apartamentos, mas verdadeiros conglomerados, que alimentam em tempo recorde uma febre imobiliária que muitos consideram envolta em uma perigosa bolha.

Os guindastes são presença constante em todas as grandes cidades. É difícil andar dois minutos de carro em Pequim sem encontrar uma obra de construção civil. Pessoas que ficam dois anos sem visitar a cidade dizem que têm dificuldade em reconhecer determinadas regiões quando retornam. Bairros inteiros são demolidos para a construção de avenidas e novos prédios, enquanto milhares de camponeses invadem a cidade para preencher os postos de trabalho da construção civil - processo que se repete em todos os grandes centros urbanos do país. Em muitas construções, os turnos são ininterruptos e os operários trabalham à noite, iluminados por imensos holofotes fixados aos guindastes. Moram em alojamentos apinhados de outros camponeses, ganham algo entre US\$ 50 e US\$ 100 por mês, não têm descanso remunerado nem assistência médica, mas continuam a chegar, empurrados pela falta de trabalho no campo" (TREVISAN, 2006: 35-36).

Adiante ela ainda aponta que,

"Os lançamentos imobiliários se multiplicam e atraem principalmente compradores chineses, que decidem investir suas economias e usar os generosos financiamentos dos bancos públicos. Muitos compram os imóveis, alugam e utilizam o dinheiro para pagar as prestações do empréstimo. Do lado dos investidores, os chineses também dominam. Empreendedores imobiliários representam o setor com maior peso na lista dos quatrocentos chineses mais ricos divulgada em 2005 no Hurum Report. Eles correspondem a $28 \%$ dos citados na relação, seguidos dos industriais, com $21 \%$ " (TREVISAN, 2006: 36-37).

Com isso, fica evidente que o espaço entra definitivamente no jogo das estratégias voltadas para 0 crescimento econômico, como uma mercadoria a ser produzida e vendida num mercado. Nos filmes de Jia Zhangke e nos seus relatos, notamos que a sua obra pode ser vista também como uma proposta de resistência a esse processo de modernização que arrasa as diferenças e a própria memória dos moradores dos lugares. Isso não significa uma atitude nostálgica no movimento de desagregação dos espaços (e das relações, dos costumes, etc.), mas sim uma atitude de questionamento sobre qual é o conteúdo dessa transformação. Assim, nesse contexto, trazer para o primeiro plano a memória dos operários e moradores de espaços que foram destruídos ou que estão em processo de desaparecimento, como o cineasta faz em 24 City, mas também em Memórias de Xangai (2010), pode ser uma atitude política e interpretativa do movimento de transformação que é vivido como se fosse inexorável, inescapável e condição de participar do "mundo". Trazer à tona a fala dos moradores e operários que têm seus espaços e relações desconstruídos é já apontar para uma interpretação possível sobre a qualidade propriamente humana do movimento de transformação. A jornalista Cláudia Trevisan também faz um contraponto dos espaços modernizados de Pequim e os espaços residuais de outros tempos, que 
permanecem como resistências e evidenciadores de outras formas de apropriação sem a mediação determinante da mercadoria. Diz ela,

\footnotetext{
"Andar pelas praças e parques de Pequim é ser transportado a um tempo que não foi afetado pelo vertiginoso crescimento das duas últimas décadas, que varreu a maior parte dos antigos bairros e trouxe a ocidentalização a bordo de redes de fast-food, danceterias e arranha-céus" (TREVISAN, 2006: 48).

"A vida comunitária reflete em grande parte a cultura dos hutongs, que aproxima os vizinhos. Depois de um passeio por essas ruelas, é inescapável a nostalgia de algo que ainda existe, mas que parece fadado à extinção" (TREVISAN, 2006: 49).
}

Nesse sentido, a urbanização avançada que vai apagando da cidade os espaços da sociabilidade de outros tempos e impondo novas formas de apropriação que se realizam como conflito e contradição, revela a crise da cidade, porque crise da vida urbana (CARLOS, 2015). Essa crise urbana é a crise da reprodução da vida na cidade, que encontra renovados elementos de interdições da apropriação concreta, dos espaços qualitativos do encontro e da reunião. $O$ que buscamos ressaltar no cinema de Jia Zhangke é a possibilidade de construirmos um conhecimento crítico através das questões propostas em seus filmes, que mostram de maneira próxima como esse processo é concretamente vivido e, por que não, as possibilidades de superação das contradições que se apresentam no real.

\section{Bibliografia}

ARANTES, Otília. Chai-na. São Paulo: Edusp, 2011.

CARLOS, Ana Fani Alessandri (Org.). Crise Urbana. São Paulo: Contexto, 2015.

FIANT, Antony. Le cinema de Jia Zhangke. No future (made) in Chine. Rennes: Presses Universitaires de Rennes, 2009, edição digital.

FRODON, Jean-Michel e SALLES, Walter (Orgs.). O mundo de Jia Zhangke. São Paulo: Mostra e Cosac Naify, 2014.

MARTINS, José de Souza. A Sociedade Vista do Abismo. Novos estudos sobre exclusão, pobreza e classes sociais. Petrópolis: Vozes, 2002, $2^{\mathrm{a}}$ ed.

SALLES, Walter. Em busca de Ulan Bator. In: FRODON, Jean-Michel e SALLES, Walter (Orgs.). 0 mundo de Jia Zhangke. São Paulo: Mostra e Cosac Naify, 2014, p.47-48.

TREVISAN, Cláudia. China. O renascimento do império. São Paulo: Planeta, 2006.

ZHANGKE, Jia. Jia por Jia. In: FRODON, Jean-Michel e SALLES, Walter. O mundo de Jia Zhangke. São Paulo: Mostra e Cosac Naify, 2014. 